\title{
Towards Machine Translation Using Contextual Information
}

\author{
Tim Cornish, Kimilazu lujjita, Ryochi Suginmra \\ \{tim,fujita,sugimun\}(risl.mei.co.jp \\ Matsushita Electric Industrial Co futd \\ Information and Communications 'Techology Laboratory
}

\section{Abstract}

A proposal is made for the use of contextuil in formation in the machine translation of dapinese and English. 'This paper describes the use of a Context Monitor to mintain contextual information dyuanically and the augmentation of appropriate features to a semantic network to entible simple inference. The approach taken is that of "best gness" processing with the contextual information being handled with semantic information on a shatlow level.

\section{Introduction}

Current Machine Thanslation (M'C) systems process input sentence by sentence. However, experience with English and Japanese hats shown that some langunges difler to such a degree that sentential transtation yields poor results. let us first compare the results of a conventional M'I system with those we expect to get for M'l witl context:

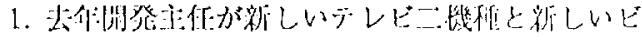



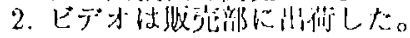

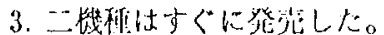

4.とても庭く光れた。

This might be translated by a curent machine translation system as shown in Figure $1^{1}$ :

It can clearly be seen that meaning in many sentences is obscured. Iet us compare this with the results of a system using simple contextnat information as shown in Pigure 2:

This second translation is much more colierent and better preserves the meaning of the original sentence.

An attempt has therefore been made to solve some of the problems of translating languages such as Japanese and Hinglish using contextual infornation. Due to the considerations of wanting to produce it high quality small-sized MT system, the appronch taken is to use the resources available in an existing M'I system and to process the contextual information

\footnotetext{
1'here is obviously a great difrerence in results bet ween systems, but these translations represent typical (tureliterl) result from a number of systems, a) and b) options depend on the default settings of individual systems
}

1. The Chief Development Fngineer developed two new 'l'V models and fonr new video moddis last year.

2. a) $A$ video was shipped to the Sales Section.

b) We/Someone shipped a video to the Sales Section.

3. a) J'wo models were released straight away.

1) We/Someone relcased two models straight away.

4. It sold very woll

ligure 1: Conventional MT Results

1. The Chiof Development Engineer developed two new 'TV models and four now video moddis last yeatr.

2. He shipped the videos to tho Silles Section.

3. 'lhey released two models straight away.

4. They sold very well.

Figure 2: Contextnal M'T Results

on a shallow level only, using the information gained to guite the translation on a "best guess" basis. 'This kiud of feature with rather light processing for the production of a higher quality transhation is desirable in a praclical $\mathrm{M} T$ system because the ardvantages of large-scale processing for deep contextual information are likely to be limited in this application.

\section{The M'T System}

The: transhation system presented here is a molel systen which is being used to investigate the technigues proposed. The translation part is carried ont in PROLOQ using an THG-like grammatical formalism ". The enrent dictionaries conbain information to tratsslate about 300 words. There are 350 grammar rules which cover a wide range of sentence patterus.

the context monitor operates using information retrieved from the f-structure of a sentence alter analysis. 'This informalion is then used during the transfer

\footnotetext{
Tlas orgenal program for lidhglish-Spanish translation developed by G. Amores [Amores so] las been widely adapted

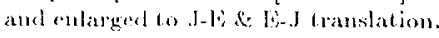


of the source fstructure to the target fstructure. As context processing is carried out on only a shallow level, only information for lexical item, number, person, gender, case role etc is used in the context system, along with semantic information from the semantic network. 'l'he way that this information is used will be explained below in regard to the specific problems that the use of context is intended to resolve.

\section{The Context Monitor:}

The context monitor proposed in this paper uses a standard focussing theory as a basis ([Sidner 81]), [Sidner 86]), although somewhat simplified according to the best guess approach that we are adopting. It is planned to increase the complexily of this initial algorithm to reflect more current versions of the theory as the system is developed.

The context monitor has a number of basic data structures: Current Focus, Actor Focus, l'otential Fo. cus List, Potential Actor Focus List, Discourse Segment Stack and Actor Focus Stack. Phere is also a Current State List that maintains a record of all the semantic items currently leedel in any of the other data structures and the semantic features to which they are linked. This list is updated (entries added and removed) after every sentence.

In order to limit the scope of the context informat tion required in the context monitor, an malysis was made of the main differences between Japanese and Finglish that provide problems for M'T' systems. 'Tlue basis of the analysis was to find what information can be gained from context to solve these problems.

\subsection{Plural Forms}

Japanese is (in generalis) unmarked for number. Whglish, however, differentiates between singular and plural. This fact causes problems when transhating from Japanese to English as the mumber information required for the inflection aurl declension of English is not available from the analysis of the Japanese. For example:

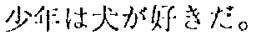

$$
\begin{aligned}
& \text { (boy }(s)_{s u b j} \operatorname{dog}(s)_{o b j} \text { likic) } \\
& \left\{\begin{array}{l}
\text { The boy likes the dog. } \\
\text { The boys like the doy. } \\
\text { The boy likes the dogs. } \\
\text { The boys like the dogs. } \\
\text { Boys like dogs. }
\end{array}\right.
\end{aligned}
$$

In the current system an initial sentence analyzed by the system is processed to find possible foci. Itens which are in the plural or are in conjunction are stored as a set. 'The set as a whole is given plural number,

\footnotetext{
${ }^{3}$ Note the use of $\mathrm{X}$ ('lachi') with manly people and animals,

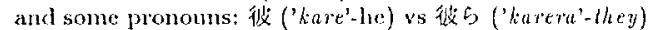

but consists of individual items or, as in the case of "lwo new TV models and four new video models", as subset.s. Subsets or inclividual items within the sets are available as antecedents to subsequent referring expressions.

Thus, in the example text in Section 1, after the initial sentence is analysed, the proposed locus is two new TV models and four new video models, the structure of which is shown in Figure 3 below:

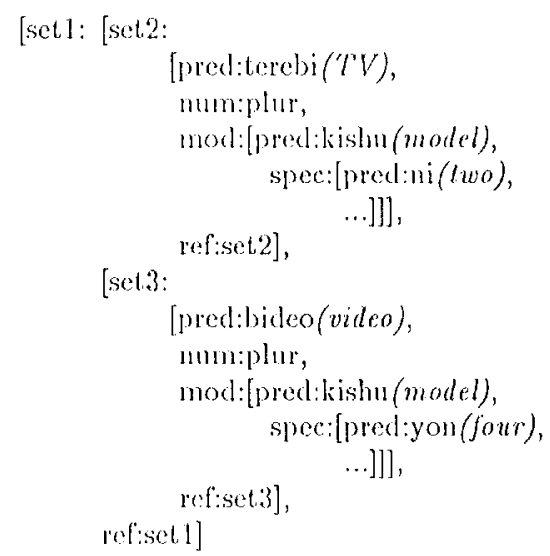

ligure 3: PROLOG Structure

Sentence 2 (S2) is analysed and a test is made to see if any items in that sentence confirm or reject the proposed focus. 'The structure for the iten ビグ ("a vicleo/videos") is matcher by mification with the structure for the proposed focus and can be matelied

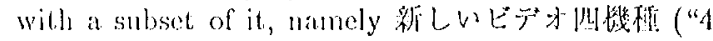
new video models"). "What itrom is therefore taken to confirm the proposed focus.

'That proposed focus is, however, immediately pUSiled onto the focus stack because the subset of 4 videos is taken as the current, focus ${ }^{5}$. The item ヒ̈デオ of $\$ 2$ inherits the fentures of the set of videos from $S t$ and is therefore expressed in the English willt a phomal form: "vidcas". It is hoped that in this way the context monitor will be able to distingnish between singular and phual in at least some cases.

In some cases there is no way of distinguishing betwech singular and plutal reference in Japanese as in the case of the sentence below:

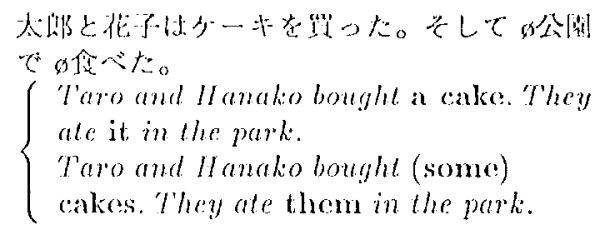

\footnotetext{
${ }^{1}$ in a simplified form, showing relevan detail ouly. Ihalics are tratastions for explanation only and do not appear in the structure proper

FThe system cormenty deals only with local focus - there is no account of globat focus
} 
In such cases the context monitor cannot resolve: singular or plural and so the M'I' system defiult will be relied on. Ilowever, the context monitor at least allows for coherence wilh subsequent pronouns.

\subsection{Translation of Pronouns}

Japanese makes much use of the zero pronoun (marked here by " $\phi$ "), especially in the subject position, but equally for other roles. Fior example:

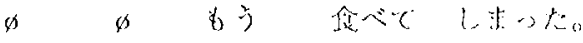

$$
\begin{aligned}
& \text { ( } \phi \quad \phi \text { mon tabete shinatitia) } \\
& \left(\phi_{s u b j} b_{o b j} \text { already cal } A U X\right\} \\
& \left\{\begin{array}{l}
\text { (I) have already eaten (it) } \\
\text { (Ihey) have already eaten (them) } \\
\text { (IJe) has already calen (them) } \\
\text {.. }
\end{array}\right.
\end{aligned}
$$

This means that there is no information avaliable from the single sentence to aid the choice of muluvalont. linglish pronoun (which must normally be expressed). As shown in 2 and 3 of the example texi in ligure 1 , M'L' systems use at mumber of methods to ald an overt. pronoun, often involving the user in the final choice.

It is claimed that if there is a pronoun in it sentence, it must refer to the focus of that text segment (in order to continue the carrent segnent) and if there are more than one pronoms, at least one of them must reler to the focus. By tracking the focus of a text segment, a pronouns in Japanese should be able to be resolved so that an appropriate overt pronoun in linglis; (an be selected for the transtation.

When a zero pronoun is detected in a sentence, il an antecedent can be found for it, and that antecedent, is a set of items, the overt pronoun inserted in line Finglish will be plural.

'T'hus in 4 of the example from figure 2, we see that

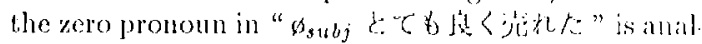
ysed as referring to the two video models released and is therefore translated with a pluat pronoun: "They soll very well'.

Note, however, that there is ambignity in sontence

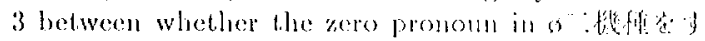

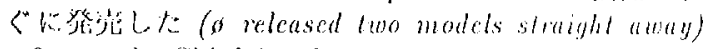
refers to the Chief Development lingineer or the Siles Section.

When faced with anbiguty such as this, large-seale: attempts at context understanding night use inference plans to solve the ambiguity. IJowever, beciuse of the linitations of a small size $\mathrm{N}^{\prime} \mathrm{I}^{2}$ system and the fact that even large scale decp level semantic processing has not been satisfactorily realised for mulinited domains (with which our M'l' system is intended to work), we decided to attempt limited inferencing by the addition of some features and links to t.hes semint tic network of the MT system. 'The inferencing able to be performed by such a method is quite simple, but. is loped to be sufficient for our needs in accordance with the best guess policy.

\subsection{Semantic Networks}

Semantic networks are bisically a hierarchy of concepts which are linked to one another in a network type structure. Semantic networks were introduced by Quillian in 1968 [Quillian 63] and were widely used in athempts at Knowledge Based Systems, particnlarly chring the latte 1980)s.

As an example of such a systen let us briefly consider the system for Japanese-finglish translalion nsing contextual information proposed by 11 . Lsalaara aud S. Ishizalie ([Lahaura 86], [Lsahalra 87], [1shimaki 89] and [Isahama 90]) as one Knowledge Based approach and compare it to the techniques used in the systen proposed in the curent paper.

'The transiation system CONTRAST translated Japanese newspaper articles inte English. However, a major diflerence regrading our system is that con. text understanding involved analysing a sentence $A$

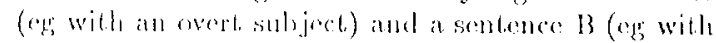
a covert subject) and then thateding these sentencess agininst at mubler of sentence palterens. If a malch wats found these would form a text, paltern $G$, with $A$

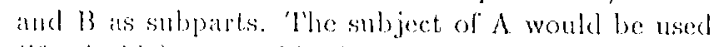
(if suitable) to provide the subject for B. By adding furtler sentences and toxt palterns, al representation ol the entire text would be formed and this text repre. sentation translated into an lingtislt equivalent text.

However, this techuigue relies on the fact that you call predict all the types of sentence that will oceur and how they combine to form an entire text (per hiaps possible for the types of newspaper articles the (ON'RAST system anded to translate). However, if a sentence cambot fit into one of the preprepared pat. terns, the system will fail. Onr system is intended for tuore general langmage and as we camol predict the length of a text or what kinds of sentence will oecur within that text, the Context Monitor provides on. going contextual analysis without prepresuming the length or mature of the text.

CON'TRAST also melies on making a mepesentar lion of the entipe lext. In onte system there is mo understanding of the overall text structure (according, to our shallow level approbach). Instead, the oljects and events referred to in the text are analysed and matre available lo resolve subsequent analysis problens. The transhation remains sentence by sentence, allhonght the general context of the text is monitored.

Finally, Semantic Neworks, such as that proposed by lsalarat ot al., are static networlis. The links do not change hetween nodes. The possible paths that are available thomgh the network may change but the links themselves clo not change. In our system, the basic semantic network is static, defining iredialable relations betwen the concepts in the hierarehy, but on top of this, other links are anguented onto the 
network and these links can change dynamically in respect to the specific objects and concepts referred to in the text. This provicles a powerful augmentation to the basic network.

\subsection{The Augmented Semantic Net- work}

The semantic network in this system is basically a hierarchy of Objects, States and Events. The acldition of features to the semantic network in effect adds links to the network. Two kinds of link are proposed: permanent links and temporary links. Permanent links are conditions that must be true for a certain action or state-of-aflairs to hold. The other, temporary, links are used to create a default state for the objects mentioned in the text. As the text is processed, these links may change, so that the information available to the system will differ from one sentence to the next.

\subsubsection{The Links}

The division between Objects, States and Events is reflected in the type of feature given to semantic items. For example, Events typically contain features about the sort of things that are affected by that event; States contain information the types of objects that. may be in that state; Objects contain information about any subparts or if they themselves are typically part of another (larger) object and what type of Event they are typically involved in.

On this basis, the following types of link are proposed:

* Condition ( $=c)$ : (permanent) a condition that must hold for a State or Event to come about.

$\star$ Before Condition (BC::): (permanent) a condition that must be true before an Event or State comes about.

* After Condition ( $\Lambda \mathrm{C}::$ ): (permanent) a condition that becomes true after an livent or State comes about.

* Ilas Subpart (has): (temporary) an Object has related subparts or is a subpart of another Object.

* Characteristic (has Semantic_Label): (Lemporary) an Object has the characteristic of Semantic.Label (usually an Abstract_Relation: Size, Shape Colour etc.). This takes the form of: "Item has Semantic_Label", such as "Peterlias Existence Lifespm". This states that an item with the semantic item $P e$ ter has an existence of some kind and further locates that item on a path of the network to the abstract relation of lifespan. In this way, nodes between these two points are all available for reference by the in ference system.

* Ability (able_to): (temporary) This is not fully defined in the current system but represents characteristic features of items e.g. "dloor" often appears in the theme position of the Events Open and Shul.
These links are considered sufficient for the current capabilities of the system. links may be deleted or others added as the range of the sytem widens, if this is thought necessary or desirable.

\subsubsection{Permanent \& Temporary Links}

The diflerence between permanent and temporary links is in the nature of the information that they convey. Permanent links are those that are augmented to the network and connect nodes one to the other in accordance with the features found in those nodes. "Before Condition and Afler Condition links are permanent, although the information contained in the nodes that they connect to will only become available to the context monitor in accordance with the tense and aspect of the verb (i.e. an After Condi. tion is obviously only valid after the completion of the (for example) action denoted by a verb has finished. Temporary links are those that supply default information to the context monitor concerning nodes that it is concened with. Mhus, for eximple, an entry for a bird mighte state that it is Able_'lo lyly. However, if the injut text were to state that a particular bird is unable to fly, that Able. To link would be cancelled. Thus temporary links provide the information that the context monitor uses, using the temporary links to spread throughout the network (within set search constraints) and gathering information that can be used for inforencing.

\subsubsection{Example of the Augmented Features}

An example of the features used to augment the senantic network can be given using the example:

Peter heard that John had died. Ile was very sad.

Given the dictionary entry shown (here simplified) below, "Petcr" will be anilysed as a male proper noun.

$$
\begin{aligned}
& \text { dic(n,'Peter', [semfont: [human:yes], } \\
& \text { proper:yes, } \\
& \text { gender:masc, } \\
& \text { predpeter]). }
\end{aligned}
$$

When the embedded clanse is analysed, "John" will be analysed in a similar way. The semantic feature human:yes locates these two lexical items as subsumed by the semantic feature "Living" in the network. Augmented features for a male humau such as the objects refered to by the names Peter and John are shown below in Figure 4 below along with possible entries for the Event die and the State be sad.

It can be seen that one of the Before Conditions of the livent Die is that the actor role is filled by an item that has the semantic reature "Tiving". The clefault assumption for "John" is that he is IIuman 


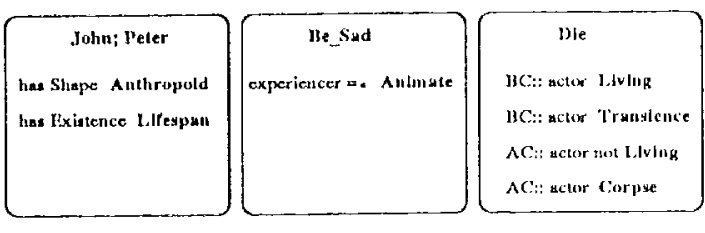

Figure 4: Augmented Peatures

and therefore living. Iowever, the After Conditions of the Event Die cancel the feature Living in connection with "John" ('nol'means that a leature and all the other features underneath it in the tree should not be reachable by that item), and state that the item should be associated with the feature "Corpse" (a semantic label in the system for something that was living but is no longer). Thus the semantic item "John" is first linked with the semantic feature "Human" and all the other leatures inherited from that feature. Ilowever, the features associated with the semantic item "Die" cause the links associated with "John" to change. 'This means that when the second sentence is analysed, the possible candidates for the experiencer role of the semantic item "BCSAt" are analysed, an item with the semantic feature " $\mathrm{N}$ inate" will be sought, and so the iten "John" will not be considered in the search as it is no longer on a path reachable by "Animate". "Peler" is therelore the only possible antecedent.

\subsection{Articles}

Japanese does not use definite and indefinite articles and so when there is no overt determiner in the Japanese, one must be supplied for the English translation. For example, Sentence 2 of our eximple text:

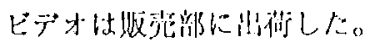

'They passed the videos to the Sales Section.

Where a simple defuult rule is used for articles, this could equally be machine translated as: they pussed videos to the Sales Division ${ }^{6}$, where it can be considered that some of the sense of the original sentence is lost.

While the use of contextual information cambot solve all of the problems of articles, it is lopped that at least in some cases incorrect possibilities can be climinated (following the "best guess" policy). In the cases that the context monitor camnot decide an article, the MT system default will be relied upon.

'To decide between a definite and indefinte article in English, a simple rule of thumb in the present system is that once an olsect has been specified in a context,

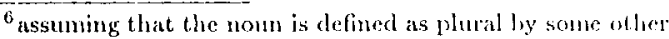
process, otherwise a video is also a possibility
}

all sulsecquent references to that partictlar object in the same context will be definite?

In the method proposed here, as objects are analysed, they are given a unique reference mumber (ref) that separales them from all other oljects of the same type. Thus, the first time that an object is analysed, it will be made indefinite, mless the reference can be analysed as being; a generic one (c.gi. The lion is a dangerous animal etc).

From then on, if an item in the text an be linked to an item which is the current focus, a potential focus or an iten on the focus stack, it will be made definite in the linglish transtation. 'Therefore, the two video models of Sentence 3 are recognised as a subset of the four videos that form the focus and are given the definte article.

Note also that as subparts of objects are included in the features attached to semantic items using the has feature, objects related to in iten already mentioned cau also be treated to some extent and translated with sefinite articles:

\section{Ianalio bouglit a new video. Sho look it back to the shop as the tape head was damaged.}

'This, however, a very simple approach and camol, account for all possible uses of the definite/ indefinite arlictes. However, the approach outlined above also follows the "best guess" strategy; where this strategy fails the nomal delauld rules of the translation system take over.

\subsection{Restrictions on the Repetition of Pronouns}

In Englisl, overt pronouns are repeabable and in some catses obligatory in a sentence to preserve meaning, In Japranese, however, overt pronouns are not repeatable as shown in the belows.

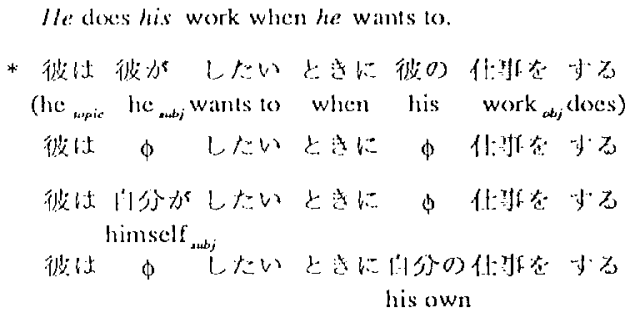

It is therefore desirable to have a routine in an $\mathrm{MT}^{\mathrm{T}}$ system to replace overt pronoms in English with o or l'l 分 ('jitun' oneself) in Japanese. In this case, the use of the pronom he in English will be analysed and recognised as referring to the same person using

\footnotetext{
This basic principle is supplemented by rules based on syntat:tic constructions ato

8'llis exanple taken from [Warla 90]
} 
the processes outlined above. Separate rules concerning co-occurrence of pronouns can then be used to substitute $\phi$ or 1分 ('jibun' himself) in the Japanese translation.

\section{Limitations \& Problems}

As shown above, the inferencing carried out is very simple. It depends entirely on the links between nodes of the network and there is an obvious limit as to how complicated those links may become before the processing required to search all the nodes linked to a particular item becomes prohibitive. $A$ t the current stage of planning, a structure (a semantic item) may be linked to another via one node (constrained to be an Abstract Relation). There are no current plans to increase the number of such linking nodes.

The inference mechanism is also expected to perform poorly where actions denoted by a verb al'e conlplex. 'This is due to the very simple feature descriptions that we use in the system. It might therefore be desirable that, if the processing is not completed within, for example, a constrained time, the process be terminated and the context monitor left to rely on semantic feature matching alone.

Another major problem is writing the falutues for the links in the network. At the moment, all features are written by hand, but it is hoped that similar in. formation might be extracted from semantic and caseframe dictionaries.

The context monitor is currently written in PRO $\mathrm{LOG}^{9}$. The program currently consists of several hundred lines of PROLOG.

\section{$6 \quad$ Final Remarks}

The idea of using contextual information in Machine 'Translation has been proposed before (for example [Wada 90], [Eberle 92], [Iaenelt 92]), however, there seems to be litule researeh carried ont in the field. MT research still secms to take the sentence as the basic unit of translation and the quality of their raw output suffers as a result. We have proposed how some of the errors of J-F \& F-J transtation can be solved and have outlined a Context Monitor with simple inferencing.

The best guess approach tries to define a problem and specify the information needed to solve that problem. The context monitor system searches for specific information from the input sentence and il it, cannot, find it, it simply does nothing, allowing the defiults of the translation system to supply the necessiny information. The search routines of the context monitor look for that specific information at as earlier a stage as possible in the process and so if that informalion is

\footnotetext{
${ }^{9}$ Not all of the fealures mentioned in this paper are currently implemented
}

not found, the next rontine is tried as quipkly as possible in order not to decrease the overall translation speed by a significant amount.

Even when the context monitor fails and the MT system defaults are relied upon, the context monitor ensures consistency with subsequent sentences.

Complicated texts are likely to leal to the Context Monitor failing often but it is still felt that the better translation produced in many more cases and the fact that interference with the specd of the translation is negligible mean that the prospects for a compactsized personal M'T' system producing better quality translations are very pronising.

\section{References}

[Amores 89] G. Anores, MSc. Dissertition, UMTST, 1989.

[Eberle 92] K. Eberte, W. Kasper, C. Rolure, Contextual Constraints for MT, TML-92 Procedings, p)213-224.

[Itachelt 92] K. Hacuelt, Towards a Quality Improvement in Machine Transtation: Modelling Discourse Structure und Including Disconrse Develop. ment in the Determination of Translation Equivalents, 'TML-92 Proceedings.

[Isalbata 80] II. Isahama \&. S. Islizaki, Contedt Analysis Sys tem for Japanese Texi, COLINCB,, [P]24-246.

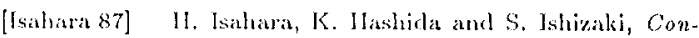
strint Based Merence for Concept Unification in Contextual Analysis (in Japanese), Proe of 35th Meeting of the Information Processing' Society of Japan, 1987, ppl240-1249.

[Ishizali 89] S. Ishizaki \& II. Isaliata, Contentual Informalion Translation System CONTRAST (in Jatpanese), Joumal of the Information l'rocessing Sociely of Japan, vel.30, 10.10, p1.105-6, 1084

[Isahama 90] II. Isaliam \&. S. Ishitalki, Natural Language Onlerstunding System with Concept Micrarthy, Proce of Pacific Rim Intemational Conference on $\left.A Y^{\prime}\right), 1$ p $322-27$.

[Quillian (i;s] M. R, Quillian, Semantic Memory, in Semuntic: luformation Processing, od M. Minsliy, 1963, p) $227-270$.

[Sidner 81] C. L. Lidnee, Fucasing for Intergrelation of Pronoums, Americat Jommat of Comput ational teinguistics, Vol. 217.213.

[Siduen 86] C. [. Siduer, focusing ith the Comprehension of Definile Araphora in Readings in Natural Ianguage Processing, eds B.J. Grus, K.S. Jumes, B.h. Weblex, 1986.

[Wadia 90] II. Warla, Miscourse Proeessing in MT: Prob. lens in Pronominal Trunsitution, COLING-90, $1073-75$ 